\title{
Clinical characteristics of COVID-19 infection in chronic obstructive pulmonary disease: a multicenter, retrospective, observational study
}

\begin{abstract}
Fan Wu ${ }^{1 \#}$, Yumin Zhou ${ }^{1 \#}$, Zhongfang Wang ${ }^{1 \#}$, Min Xie ${ }^{2 \#}$, Zhe Shi ${ }^{3 \#}$, Zhiqiang Tang ${ }^{4 \#}$, Xiaohe $\mathrm{Li}^{5 \#}$, Xiaochen $\mathrm{Li}^{6 \#}$, Chunliang Lei" ${ }^{7 \#}$, Yimin $\mathrm{Li}^{1 \#}$, Zhengyi $\mathrm{Ni}^{8 \#}, \mathrm{Yu} \mathrm{Hu}^{9 \#}$, Xiaoqing Liu ${ }^{1}$, Wenguang Yin ${ }^{1}$, Linling Cheng ${ }^{1}$, Feng Ye ${ }^{1}$, Jieqi Peng ${ }^{1}$, Lingmei Huang ${ }^{10}$, Jia Tian ${ }^{11}$, Lingjuan Zhang ${ }^{3}$, Xiaoneng Mo ${ }^{7}$, Ying Zhang ${ }^{5}$, Ke Hu ${ }^{6}$, Yongliang Jiang ${ }^{12}$, Weijie Guan ${ }^{1}$, Jie Xiang ${ }^{8}$, Yingxia Liu ${ }^{5}$, Yixiang Peng ${ }^{13}$, Li Wei ${ }^{14}$, ${\text { Yahua } \mathrm{Hu}^{15} \text {, Peng Peng }}^{16}$, Jianming Wang ${ }^{17}$, Jiyang Liu ${ }^{18}$, Wei Huang ${ }^{19}$, Ruchong Chen ${ }^{1}$, Jianping Zhao ${ }^{2}$, Shiyue $\mathrm{Li}^{1}$, Nuofu Zhang ${ }^{1}$, Jincun Zhao ${ }^{1}$, Nanshan Zhong ${ }^{1}$, Pixin Ran ${ }^{1}$; for the Medical Treatment Expert Group for COPD and COVID-19
\end{abstract}

${ }^{1}$ State Key Laboratory of Respiratory Disease \& National Clinical Research Center for Respiratory Disease, Guangzhou Institute of Respiratory Health, the First Affiliated Hospital of Guangzhou Medical University, Guangzhou Medical University, Guangzhou, China; ${ }^{2}$ Department of Pulmonary and Critical Care Medicine, Tongji Hospital, Tongji Medical College, Huazhong University of Science and Technology, Wuhan, China; ${ }^{3}$ Huizhou First Hospital, Huizhou, China; ${ }^{4}$ The Second People's Hospital of Changde City, Changde, China; ${ }^{5}$ Shenzhen Third People's Hospital, Shenzhen, China; ${ }^{6}$ Renmin Hospital of Wuhan University, Wuhan, China; ${ }^{7}$ Guangzhou Eighth People's Hospital, Guangzhou Medical University, Guangzhou, China; ${ }^{8}$ Wuhan Jinyintan Hospital, Wuhan, China; ${ }^{9}$ Institute of Hematology, Union Hospital, Tongji Medical College, Huazhong University of Science and Technology, Wuhan, China; ${ }^{10}$ The First people's Hospital of Yueyang, Yueyang, China; ${ }^{11}$ The Second People's Hospital of Hunan Province, Changsha, China; ${ }^{12}$ Department of Respiratory and Critical Care Medicine, Hunan Provincial People's Hospital, Changsha, China; ${ }^{13}$ The Central Hospital of Wuhan, Wuhan, China; ${ }^{14}$ Wuhan No. 1 Hospital, Wuhan Hospital of Traditional Chinese and Western Medicine, Wuhan, China; ${ }^{15}$ Huangshi Central Hospital of Edong Healthcare Group, Affiliated Hospital of Hubei Polytechnic University, Huangshi, China; ${ }^{16}$ Wuhan Pulmonary Hospital, Wuhan, China; ${ }^{17}$ Tianyou Hospital Affiliated to Wuhan University of Science and Technology, Wuhan, China; ${ }^{18}$ The First Hospital of Changsha, Changsha, China; ${ }^{19}$ Jiangling County People's Hospital, Jingzhou, China

Contributions: (I) Conception and design: P Ran, N Zhong, Y Zhou; (II) Administrative support: None; (III) Provision of study materials or patients: M Xie, Z Shi, Z Tang, X Li, K Hu, C Lei, Y Li, Z Ni, Y Hu, X Liu, L Cheng, F Ye, L Huang, J Tian, L Zhang, X Mo, Y Zhang, X Li, Y Jiang, W Guan, J Xiang, Y Liu, Y Peng, L Wei, Y Hu, P Peng, J Wang, J Liu, W Huang, R Chen, J Zhao, S Li, N Zhang, J Zhao; (IV) Collection and assembly of data: F Wu, Y Zhou, J Peng, W Guan; (V) Data analysis and interpretation: F Wu, Y Zhou, Z Wang, W Yin, P Ran; (VI) Manuscript writing: All authors; (VII) Final approval of manuscript: All authors.

"These authors contributed equally to this work.

Correspondence to: Pixin Ran, MD, PhD. State Key Laboratory of Respiratory Disease, National Clinical Research Center for Respiratory Disease, Guangzhou Institute of Respiratory Health, The First Affiliated Hospital of Guangzhou Medical University, 151 Yanjiang Road, Guangzhou, China. Email: pxran@gzhmu.edu.cn.

Background: Coronavirus disease 2019 (COVID-19) has been a global pandemic disease, with more than 4 million cases and nearly 300,000 deaths. Little is known about COVID-19 in patients with chronic obstructive pulmonary disease (COPD). We aimed to evaluate the influence of preexisting COPD on the progress and outcomes of COVID-19.

Methods: This was a multicenter, retrospective, observational study. We enrolled 1,048 patients aged 40 years and above, including 50 patients with COPD and 998 patients without COPD, and with COVID-19 confirmed via high-throughput sequencing or real-time reverse transcription-polymerase chain reaction, between December 11, 2019 and February 20, 2020. We collected data of demographics, pathologic test results, radiologic imaging, and treatments. The primary outcomes were composite endpoints determined by admission to an intensive care unit, the use of mechanical ventilation, or death.

Results: Compared with patients who had COVID-19 but not COPD, those with COPD had higher rates

(c) Journal of Thoracic Disease. All rights reserved. 
of fatigue $(56.0 \%$ vs. $40.2 \%)$, dyspnea $(66.0 \%$ vs. $26.3 \%)$, diarrhea (16.0\% vs. $3.6 \%$ ), and unconsciousness $(8.0 \%$ vs. $1.7 \%)$ and a significantly higher proportion of increased activated partial thromboplastin time (23.5\% vs. $5.2 \%)$ and D-dimer (65.9\% vs. $29.3 \%$ ), as well as ground-glass opacities ( $77.6 \%$ vs. $60.3 \%)$, local patchy shadowing $(61.2 \%$ vs. $41.4 \%)$, and interstitial abnormalities $(51.0 \%$ vs. $19.8 \%)$ on chest computed tomography. Patients with COPD were more likely to develop bacterial or fungal coinfection $(20.0 \% v s$. $5.9 \%$ ), acute respiratory distress syndrome (ARDS) (20.0\% vs. $7.3 \%)$, septic shock (14.0\% vs. 2.3\%), or acute renal failure (12.0\% vs. 1.3\%). Patients with COPD and COVID-19 had a higher risk of reaching the composite endpoints [hazard ratio (HR): 2.17, 95\% confidence interval (CI): 1.40-3.38; $\mathrm{P}=0.001$ ] or death (HR: 2.28, 95\% CI: 1.15-4.51; $\mathrm{P}=0.019$ ), after adjustment.

Conclusions: In this study, patients with COPD who developed COVID-19 showed a higher risk of admission to the intensive care unit, mechanical ventilation, or death.

Keywords: Clinical characteristics; chronic obstructive pulmonary disease (COPD); coronavirus disease 2019 (COVID-19)

Submitted May 13, 2020. Accepted for publication May 19, 2020.

doi: $10.21037 /$ jtd-20-1914

View this article at: http://dx.doi.org/10.21037/jtd-20-1914

\section{Introduction}

Coronavirus disease 2019 (COVID-19) is a global pandemic and led to more than 4 million infections and nearly 300,000 deaths worldwide, according to data released by Johns Hopkins University on May 11, 2020 (1-3). A large study from China showed that $23.7 \%$ of patients with COVID-19 had at least one preexisting chronic underlying disease or comorbidity; among severe cases, this rate increased to $40 \%$ (4).

Chronic obstructive pulmonary disease (COPD) is the most common chronic respiratory disease in China, with a prevalence of $13.7 \%$ among people 40 years of age or older (5). It has been reported that older people and male individuals are more susceptible to developing COVID-19, which is a demographic pattern similar to that of COPD. Therefore, it is important to evaluate the influence of preexisting COPD on the progression and outcomes of COVID-19. A previous study showed that the percentage of patients with COVID-19 and comorbidity of COPD was $1.5 \%$; severe cases with underlying chronic pulmonary diseases accounted for $5.9 \%$ in the studied populations (6). Notably, mortality among patients with COVID-19 and chronic pulmonary diseases is $50 \%$, much higher than the $25 \%$ in other patients with COVID-19 (7). However, considering the cohort size, a more detailed description of the clinical characteristics of patients with COPD and COVID-19 is necessary and fundamental to understanding the risk of COPD in COVID-19. Such evidence will be useful for future prevention and therapy.

In this study, we collected clinical information from 1,048 patients aged 40 years and older with confirmed COVID-19, and we compared patients with and without COPD in terms of epidemiology, demographics, pathologic test results, radiologic imaging, and treatments. In the above comparison, we demonstrated that patients with preexisting COPD who develop COVID-19 have a greater risk of poorer outcomes. We address the importance of improving self-care as well as diagnosis and treatment in these patients. We present the following article/case in accordance with the STROBE reporting checklist (available at http://dx.doi. org/10.21037/jtd-20-1914) .

\section{Methods}

\section{Study design and participants}

In this retrospective case study, we collected data from the medical records of 50 patients with laboratoryconfirmed COVID-19 and COPD. We compiled data for hospitalized patients and outpatients in hospitals throughout Hunan, Hubei, and Guangdong provinces as well as cases reported to the National Health Commission of the People's Republic of China. Detailed information about the source of participants and hospitals is shown in the online Supplementary file. Patients with laboratoryconfirmed COVID-19 without COPD were included as controls. Among patients with COPD and COVID-19, the 
youngest was 48 years old. To avoid selection bias, we only analyzed individuals aged 40 years or above. COVID-19 was confirmed via a positive result on high-throughput sequencing or real-time reverse transcription-polymerasechain-reaction (RT-PCR) assay using nasal or pharyngeal swab specimens $(8,9)$. All patients with COPD were previously diagnosed by a respiratory physician based on spirometry [post-bronchodilation forced expiratory volume in 1 second $\left(\mathrm{FEV}_{1}\right) /$ forced vital capacity $\left.(\mathrm{FVC})<0.7\right]$ and respiratory symptoms (i.e., cough, expectoration or shortness of breath, and so on) (10). Among 50 patients with COPD, 12 were previously described by Guan et al. $(4,6)$.

This was a retrospective case study. The Ethics Commission of the First Affiliated Hospital of Guangzhou Medical University approved the study (No. 2020-51). Because of the urgent need to collect data on this emerging infectious disease, the requirement for written informed consent was waived.

\section{Data collection}

The collected information included demographic data (sex, age, height, weight, and smoking history), symptoms (fever, nasal congestion, cough, expectoration, shortness of breath, headache, muscle and joint pain, general weakness, nausea and vomiting, diarrhea, tonsillar enlargement, lymphadenopathy, rash, and unconsciousness), results of laboratory tests on admission (blood cell counts, blood biochemistry, hepatorenal function, coagulation function, D-dimer, C-reactive protein, procalcitonin, arterial blood gas analysis), chest X-ray or computed tomography (CT) imaging findings on admission (ground-glass opacities, local patchy shadowing, bilateral patchy shadowing, and interstitial abnormalities), comorbidities (hypertension, coronary heart disease, diabetes, cerebrovascular diseases, hepatitis B infection, cancer, chronic renal disease, and immunodeficiency), treatments [nasal catheter oxygen therapy, noninvasive ventilation, mechanical ventilation, extracorporeal membrane oxygenation (ECMO), intravenous antibiotics/antifungal drugs, antiviral drugs, systemic glucocorticoid therapy, gamma globulin, and continuous renal replacement therapy (CRRT)], and clinical outcomes [length of hospital stay, intensive care unit (ICU) admission, discharge, or death].

Acute respiratory distress syndrome (ARDS) and septic shock were defined based on World Health Organization interim guidance for COVID-19 (11). Acute renal injury was determined according to serum creatinine level. Evaluation of the degree of illness severity was judged according to the Chinese management guideline for COVID-19 version 6.0 (12). In brief, the disease is classified as severe if one of the following conditions is met: (I) respiratory distress, respiratory rate $\geq 30$ per min; (II) oxygen saturation on room air at rest $\leq 93 \%$; (III) partial pressure of oxygen in arterial blood/fraction of inspired oxygen $\leq 300 \mathrm{mmHg}$. The disease is classified as critical illness if one of the following conditions is met: (I) respiratory failure occurs and mechanical ventilation is required; (II) shock occurs; (III) patients with other organ dysfunction require ICU monitoring and treatment. The criteria for discharge were the absence of fever for a period of more than 3 days, obvious improvement of respiratory symptoms, absorption of lesions in the lungs as observed on chest CT, and two consecutive negative nucleic acid test results for severe acute respiratory syndrome coronavirus 2 at least 1 day apart, as well as patients who were released from the hospital.

\section{Primary outcomes of study}

The primary outcomes were composite endpoints determined by admission to an ICU, the use of mechanical ventilation, or death. These outcomes were used in our previous study (4).

\section{Statistical analysis}

We used frequency and percent to present the results of comparisons between groups. Data showing a normal distribution are presented as mean \pm standard deviation. Data without a normal distribution are presented as median [interquartile range (IQR)]. We assessed differences between groups using a two-sample $t$-test, Wilcoxon rank-sum test, and chi-square test. Considering the imbalance in the baseline data, we used logistic regression models adjusted for age, sex, smoking status, and other comorbidities at baseline to assess the difference between the COPD and non-COPD groups. Cox proportional hazards regression models were applied to determine risk factors associated with the endpoints, using backward elimination: the LR method was used, with correction factors including age, sex, smoking status, and other comorbidities (hypertension, coronary heart disease, diabetes, cerebrovascular diseases, hepatitis B infection, cancer, chronic renal disease, and immunodeficiency). We report hazard ratios (HRs) and $95 \%$ confidence intervals (CIs). Statistical analyses were performed using IBM SPSS 24.0 software (IBM Corp., Armonk, NY, USA). $\mathrm{P}<0.05$ indicated statistical significance. 


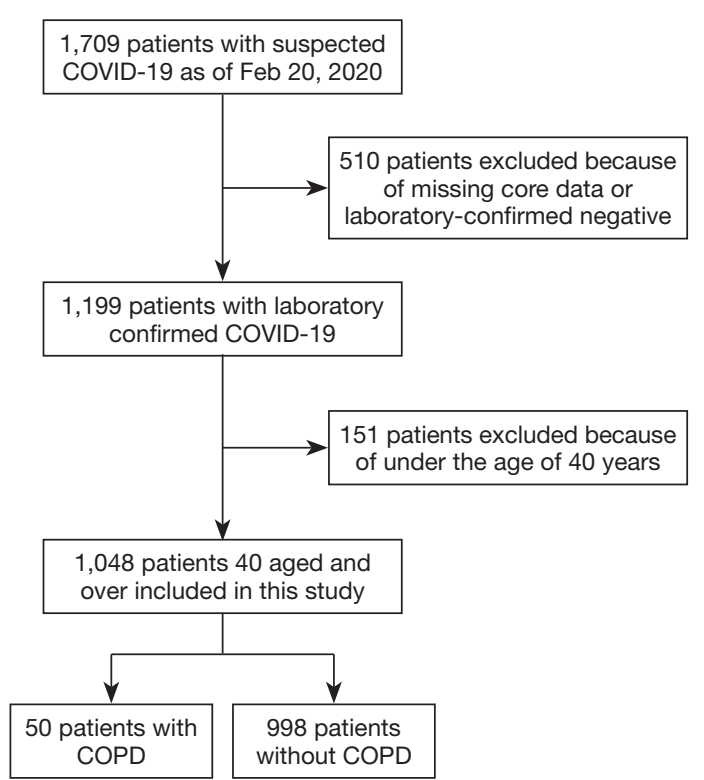

Figure 1 Flow chart of study participants. COVID-19, coronavirus disease 2019; COPD, chronic obstructive pulmonary disease.

\section{Patient and public involvement}

This was a retrospective study and no patients were directly involved in our study design, setting the research questions, or the outcome measures. No patients were asked to advise on the interpretation or writing up of the results.

\section{Results}

\section{Demographic and epidemiologic characteristics}

As of February 20, 2020, we had collected clinical data from 1,709 patients with COVID-19. We ruled out 661 cases owing to incompleteness of some key clinical data, laboratory-confirmed negative samples, or age under 40 years. A flowchart outlining the study participant selection is shown in Figure 1.

Based on these guidelines, we included 1,048 patients and $50(4.8 \%)$ had a comorbidity of COPD. Patients with COPD were older than their non-COPD counterparts [71 (IQR, 65.8-77.9) vs. 56.0 (IQR, 48.0-64.9) years], tended to be men $(83.0 \%$ vs. $55.0 \%)$ and smokers $(49.0 \%$ vs. $9.5 \%)$, and were more likely to have comorbidities ( $100.0 \%$ vs. $33.3 \%$ ) including hypertension, coronary heart disease, cerebrovascular disease, and chronic kidney disease (Table 1).

\section{Clinical features}

There were no significant differences in symptoms between patients with and without COPD, including fever $(90.0 \%$ vs. $87.0 \%)$, cough (66.0\% vs. $69.5 \%)$, and sputum production (30.0\% vs. 34.8\%). However, patients with COPD were more likely to develop fatigue $(56.0 \%$ vs. $40.2 \%)$, shortness of breath (66.0\% vs. $26.3 \%)$, diarrhea (16.0\% vs. $3.6 \%)$, and unconsciousness $(8.0 \%$ vs. $1.7 \%$;); there were still significant differences between the groups after adjustment for age, sex, smoking status, and other comorbidities at baseline (Table 1).

\section{Laboratory pathologic and radiologic findings}

Compared with patients who had COVID-19 but not COPD, whether crude or adjusted differences, the COPD group had a higher proportion of increased D-dimer $(65.9 \%$ vs. $29.3 \%)$ and prolonged activated partial thromboplastin time (23.5\% vs. 5.2\%), with significant differences (Table 2).

Compared with their counterparts, a greater proportion of patients with COVID-19 and COPD had ground-glass opacities (77.6\% vs. 60.3\%), local patchy shadowing (61.2\% vs. $41.4 \%)$, and interstitial abnormalities (51.0\% vs. 19.8\%) $(\mathrm{P}<0.05)$. However, the proportion of patients with bilateral patchy shadowing showed no significant difference between the two groups (63.3\% vs. 55.7\%) (Table 2).

\section{Treatment and complications}

A significantly higher proportion of patients with COPD and COVID-19 were treated with antifungal medication (22.0\% vs. $3.9 \%)$, systemic corticosteroids $(56.0 \%$ vs. $20.6 \%)$, oxygen therapy $(76.0 \%$ vs. $49.9 \%)$, noninvasive ventilation $(40.0 \%$ vs. $11.2 \%)$, invasive mechanical ventilation ( $24.0 \%$ vs. $4.9 \%)$, CRRT (6.0\% vs. $1.8 \%)$, and intravenous immunoglobulin ( $40.5 \%$ vs. $25.2 \%)$ than those without COPD, after adjustment (all $\mathrm{P}<0.05$ ) (Table 3).

Patients with COPD who developed COVID-19 were more likely to develop complications, including bacterial or fungal coinfection $(20.0 \%$ vs. $5.9 \%)$, ARDS $(20.0 \%$ vs. $7.3 \%)$, septic shock (14.0\% vs. $2.3 \%$ ), and acute renal failure (12.0\% vs. $1.3 \%)$, after adjustment (Table 3).

\section{Clinical outcomes}

As of February 20, 2020, in the group with COPD and 
Table 1 Clinical characteristics of the study patients

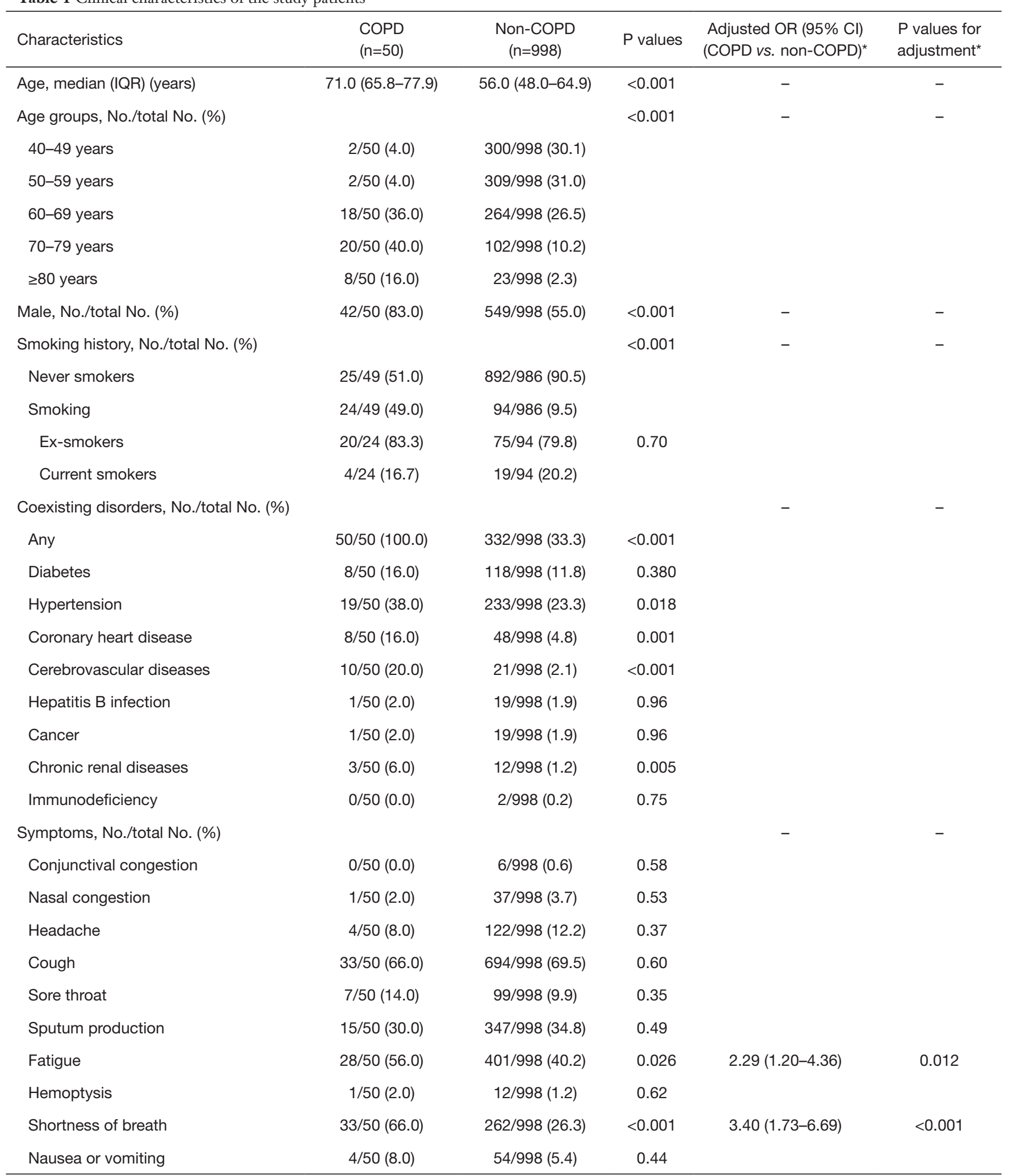

Table 1 (Continued) 
Table 1 (Continued)

\begin{tabular}{|c|c|c|c|c|c|}
\hline Characteristics & $\begin{array}{l}\text { COPD } \\
(n=50)\end{array}$ & $\begin{array}{l}\text { Non-COPD } \\
(n=998)\end{array}$ & $P$ values & $\begin{array}{l}\text { Adjusted OR }(95 \% \mathrm{Cl}) \\
(\text { COPD vs. non-COPD) }\end{array}$ & $\begin{array}{l}P \text { values for } \\
\text { adjustment }^{*}\end{array}$ \\
\hline Diarrhea & $8 / 50(16.0)$ & 36/998 (3.6) & $<0.001$ & $3.76(1.39-10.23)$ & 0.009 \\
\hline Chill & $5 / 50(10.0)$ & 109/998 (10.9) & 0.84 & & \\
\hline $\begin{array}{l}\text { Fever during hospitalization, } \\
\text { No./total No. (\%) }\end{array}$ & $45 / 50(90.0)$ & $868 / 998$ (87.0) & 0.53 & & \\
\hline $\begin{array}{l}\text { Median temperature on admission } \\
\left(\text { IQR), }{ }^{\circ} \mathrm{C}\right.\end{array}$ & $37.0(36.5-38.0)$ & $37.1(36.6-37.9)$ & 0.56 & & \\
\hline $37.5-38.5$ & $11 / 49(22.4)$ & 259/964 (26.9) & & & \\
\hline$>39$ & $5 / 49(10.2)$ & $114 / 964(11.8)$ & & & \\
\hline $\begin{array}{l}\text { Respiratory rate on admission (IQR), } \\
\text { breaths/min }\end{array}$ & 21 [20-25] & 20 [20-21] & 0.016 & - & - \\
\hline Throat congestion & $0 / 50(0.0)$ & $14 / 998(1.4)$ & 0.40 & & \\
\hline Tonsil swelling & $0 / 50(0.0)$ & $21 / 998(2.1)$ & 0.30 & & \\
\hline Enlargement of lymph nodes & $0 / 50(0.0)$ & $1 / 998(0.1)$ & 0.82 & & \\
\hline
\end{tabular}

Data are mean \pm standard deviation, $\mathrm{n}(\%)$, or median (interquartile range). $\mathrm{P}$ values for continuous variables were calculated by Student's $t$-test or the Wilcoxon rank-sum test, and $\mathrm{P}$ values for categorical variables were calculated by the chi-square test or Fisher's exact test. *, adjusted for age, sex, smoking status and other comorbidities (including diabetes, hypertension, coronary heart disease, cerebrovascular diseases, hepatitis B infection, cancer, chronic renal diseases, immunodeficiency), no significance ( $P \geq 0.05)$ was not shown in the table. Odds ratio $>1$ means that more people in COPD than Non-COPD in variables.

COVID-19, 10 (20.0\%) patients were discharged, 28 $(56.0 \%)$ were still in the hospital, and $12(24.0 \%)$ died; the corresponding rates in the group without COPD were $14.6 \%, 81.4 \%$, and $4.0 \%$, respectively. The proportion of patients with severe pneumonia $(54.0 \%$ vs. $18.8 \%)$ and critical illness (38.0\% vs. $10.3 \%$ ) in the group with COPD and COVID-19 was higher than that in the group without COPD (Table 3). The risk of composite endpoints was increased in patients with COPD (HR: 2.17, 95\% CI: 1.403.38; $\mathrm{P}=0.001$ ), with greater likelihood of death (HR: 2.28, 95\% CI: $1.15-4.51 ; \mathrm{P}=0.019$ ), after adjustment (Figure 2).

\section{Post-boc analysis}

This study included the patients with COVID-19 as of January 29, 2020 in the database of the National Health Commission of the People's Republic of China, of which 12 patients with COPD and 593 patients without COPD $(4,6)$. In order to improve credibility and integrity of this study, we excluded those patients who overlapped with Guan et al. and performed the post-hoc analysis. In posthoc analysis, there were similar to the results of the overall analysis in clinical characteristics (Table S1), laboratory findings, radiological findings (Table S2), complications, 
Table 2 Laboratory and radiographic findings of COVID-19 patients with COPD or without COPD on admission

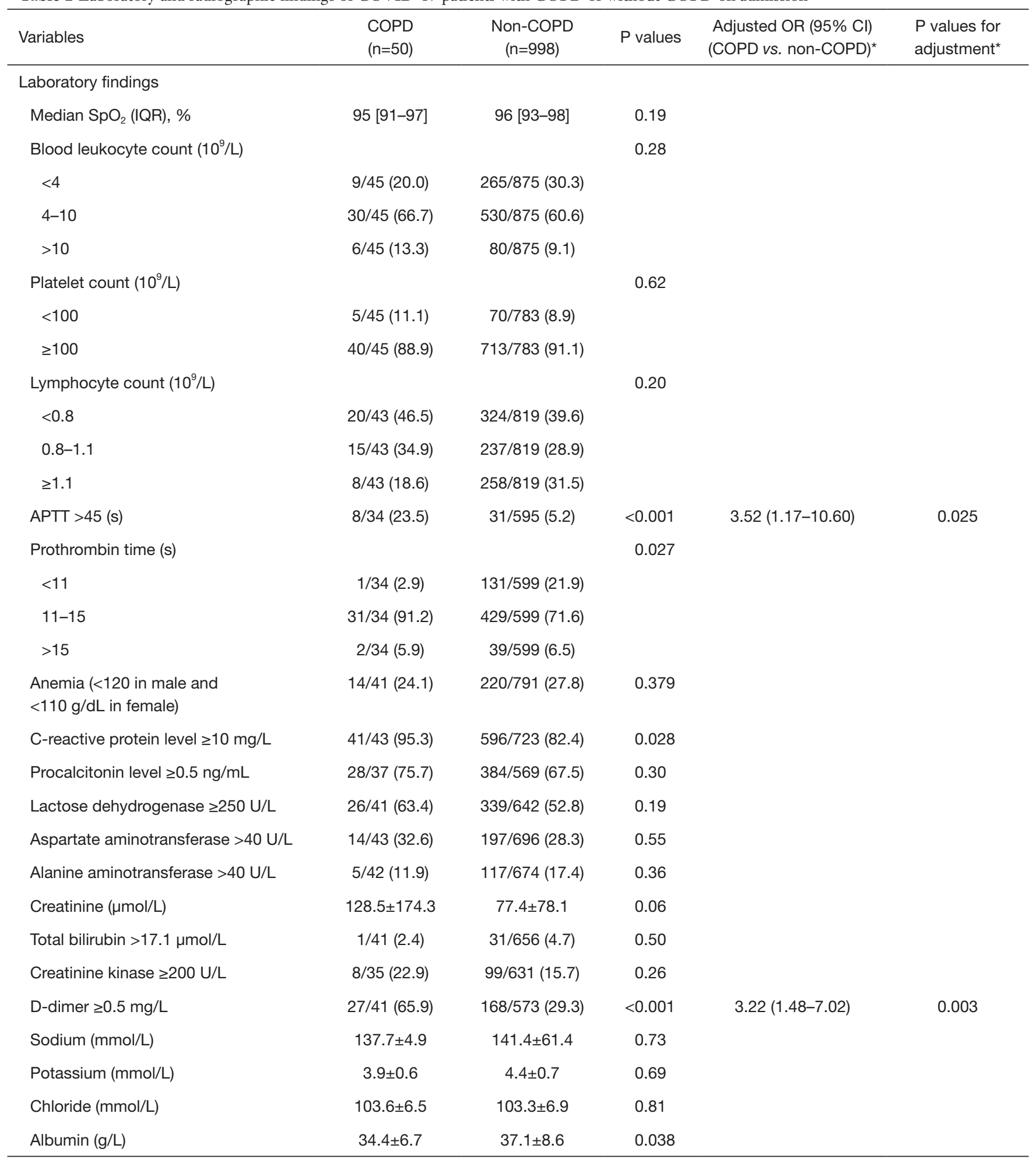

Table 2 (Continued) 
Table 2 (Continued)

\begin{tabular}{|c|c|c|c|c|c|}
\hline Variables & $\begin{array}{l}\text { COPD } \\
(n=50)\end{array}$ & $\begin{array}{l}\text { Non-COPD } \\
\quad(n=998)\end{array}$ & $P$ values & $\begin{array}{l}\text { Adjusted OR }(95 \% \mathrm{Cl}) \\
(\text { COPD vs. non-COPD) }\end{array}$ & $\begin{array}{l}P \text { values for } \\
\text { adjustment }^{*}\end{array}$ \\
\hline \multicolumn{6}{|l|}{ Radiographic findings } \\
\hline Any abnormalities & $12 / 16(75.0)$ & $197 / 271(72.7)$ & 0.84 & & \\
\hline Local patchy shadowing & $10 / 16(62.5)$ & $94 / 271(34.7)$ & 0.025 & & \\
\hline Bilateral patchy shadowing & 9/16 (56.3) & $149 / 271(55.0)$ & 0.92 & & \\
\hline Interstitial abnormalities & 2/16 (12.5) & $21 / 271(7.7)$ & 0.50 & & \\
\hline \multicolumn{6}{|l|}{$\begin{array}{l}\text { Abnormalities on chest CT, } \\
\text { No./total No. (\%) }\end{array}$} \\
\hline Ground-glass opacity & $38 / 49(77.6)$ & $528 / 875(60.3)$ & 0.016 & $4.00(1.85-8.62)$ & $<0.001$ \\
\hline Local patchy shadowing & $30 / 49(61.2)$ & $362 / 875(41.4)$ & 0.006 & $2.29(1.18-4.46)$ & 0.014 \\
\hline Bilateral patchy shadowing & $31 / 49(63.3)$ & $487 / 875(55.7)$ & 0.30 & & \\
\hline Interstitial abnormalities & $25 / 49(51.0)$ & $173 / 875(19.8)$ & $<0.001$ & $4.06(2.01-8.19)$ & $<0.001$ \\
\hline
\end{tabular}

$P$ values for continuous variables were calculated by Student's $t$-test or the Wilcoxon rank-sum test, and $P$ values for categorical variables were calculated by the chi-square test or Fisher's exact test. *, adjusted for age, sex, smoking status and other comorbidities (including diabetes, hypertension, coronary heart disease, cerebrovascular diseases, hepatitis B infection, cancer, chronic renal diseases, immunodeficiency), no significance $(\mathrm{P} \geq 0.05)$ was not shown in the table. Odds ratio $>1$ means that more people in COPD than Non-COPD in variables. Abbreviations: COVID-19, coronavirus disease 2019; COPD, chronic obstructive pulmonary; IQR, interquartile range; $\mathrm{SpO}_{2}$, saturation of pulse oxygen; APTT, activated partial thromboplastin time; CT, computed tomography.

and treatments (Table S3). The risk of composite endpoints was also increased in patients with COPD (HR: 2.18, 95\% CI: $1.22-3.90 ; \mathrm{P}=0.008$ ) after adjustment. There was a numerical increase in the risk of death in patients with COPD, with a close to statistically significance (HR: 2.28, 95\% CI: 0.93-5.59; P=0.072), after adjustment (Figure S1).

\section{Discussion}

In this study, we analyzed the clinical characteristics and prognosis of 50 patients with COPD complicated with novel coronavirus pneumonia. Compared with patients who had COVID-19 but not COPD, those with COPD had more obvious shortness of breath and hypoxemia; more abnormal laboratory and imaging findings; and greater risk for admission to the ICU, mechanical ventilation, or death, providing evidence of poor prognosis.

Although all age groups are susceptible to infection with COVID-19, older patients generally have more severe illness and poorer prognosis than younger ones $(7,13,14)$. In our study, no patients with COPD and COVID-19 were under 40 years old, which is consistent with previous reports that higher incidence of COPD occurs in people aged 40 and older $(5,15)$. To avoid participant selection bias, we only included patients who had COVID-19 but not COPD and who were aged 40 and older in this retrospective study. By limiting the age range of participants and adjusting the statistical analysis according to multiple factors, the two groups (COPD vs. non-COPD) could be more accurately compared.

To our best knowledge, this is the first report using a large sample size to analyze the clinical characteristics and prognosis of COVID-19 with COPD. Among 50 patients with COPD and COVID-19, 27 (54\%) were admitted to the ICU and required mechanical ventilation, and 10 (20\%) patients died, which is significantly higher than the overall mortality rate published in the literature $(3,4)$.

Poor prognosis in patients with COPD and COVID-19 
Table 3 Complications, treatments, and clinical outcomes of COVID-19 patients with COPD or without COPD

\begin{tabular}{|c|c|c|c|c|c|}
\hline Variables & $\begin{array}{l}\text { COPD } \\
(n=50)\end{array}$ & $\begin{array}{l}\text { Non-COPD } \\
(n=998)\end{array}$ & $P$ values & $\begin{array}{l}\text { Adjusted OR }(95 \% \text { Cl) } \\
\text { (COPD vs. non-COPD) }\end{array}$ & $\begin{array}{l}P \text { values for } \\
\text { adjustment }^{*}\end{array}$ \\
\hline \multicolumn{6}{|l|}{ Complications, No. (\%) } \\
\hline Acute respiratory distress syndrome & $10(20.0)$ & $73(7.3)$ & 0.001 & & \\
\hline Bacterial or fungal coinfection & $10(20.0)$ & $59(5.9)$ & $<0.001$ & & \\
\hline \multicolumn{6}{|l|}{ Treatments, No. (\%) } \\
\hline Administration of intravenous antibiotics & $43(86.0)$ & $680(68.1)$ & 0.008 & & \\
\hline Oxygen therapy & $38(76.0)$ & $498(49.9)$ & $<0.001$ & & \\
\hline Mechanical ventilation & $23(46.0)$ & $128(12.8)$ & $<0.001$ & $2.32(1.16-4.63)$ & 0.017 \\
\hline Invasive & $12(24.0)$ & $49(4.9)$ & $<0.001$ & $3.75(1.56-8.99)$ & 0.003 \\
\hline Non-invasive & $20(40.0)$ & $112(11.2)$ & $<0.001$ & $2.05(1.00-4.20)$ & 0.049 \\
\hline Use of ECMO & $1(2.0)$ & $9(0.9)$ & 0.44 & & \\
\hline Use of CRRT & $3(6.0)$ & $18(1.8)$ & 0.039 & & \\
\hline Use of intravenous immunoglobulin & $15(40.5)$ & $165(25.2)$ & 0.038 & & \\
\hline Reach composite end point & $27(54.0)$ & $188(18.8)$ & & & \\
\hline Clinical outcomes at data cutoff, No. (\%) & & & $<0.001$ & & \\
\hline Staying in hospital & $28(56.0)$ & $812(81.4)$ & & & \\
\hline Discharge from hospital & $10(20.0)$ & $146(14.6)$ & & & \\
\hline Death & $12(24.0)$ & $40(4.0)$ & & & \\
\hline
\end{tabular}

$P$ values for categorical variables were calculated by the chi-square test or Fisher's exact test. *, adjusted for age, sex, smoking status and other comorbidities (including diabetes, hypertension, coronary heart disease, cerebrovascular diseases, hepatitis B infection, cancer, chronic renal diseases, immunodeficiency), no significance $(P \geq 0.05)$ was not shown in the table. Odds ratio $>1$ means that more people in COPD than Non-COPD in variables. Composite end point determined by the admission to an ICU, the use of mechanical ventilation, or death. COVID-19, coronavirus disease 2019; COPD, chronic obstructive pulmonary disease; ECMO, extracorporeal membrane oxygenation; CRRT, continuous renal replacement therapy; IQR, interquartile range. 

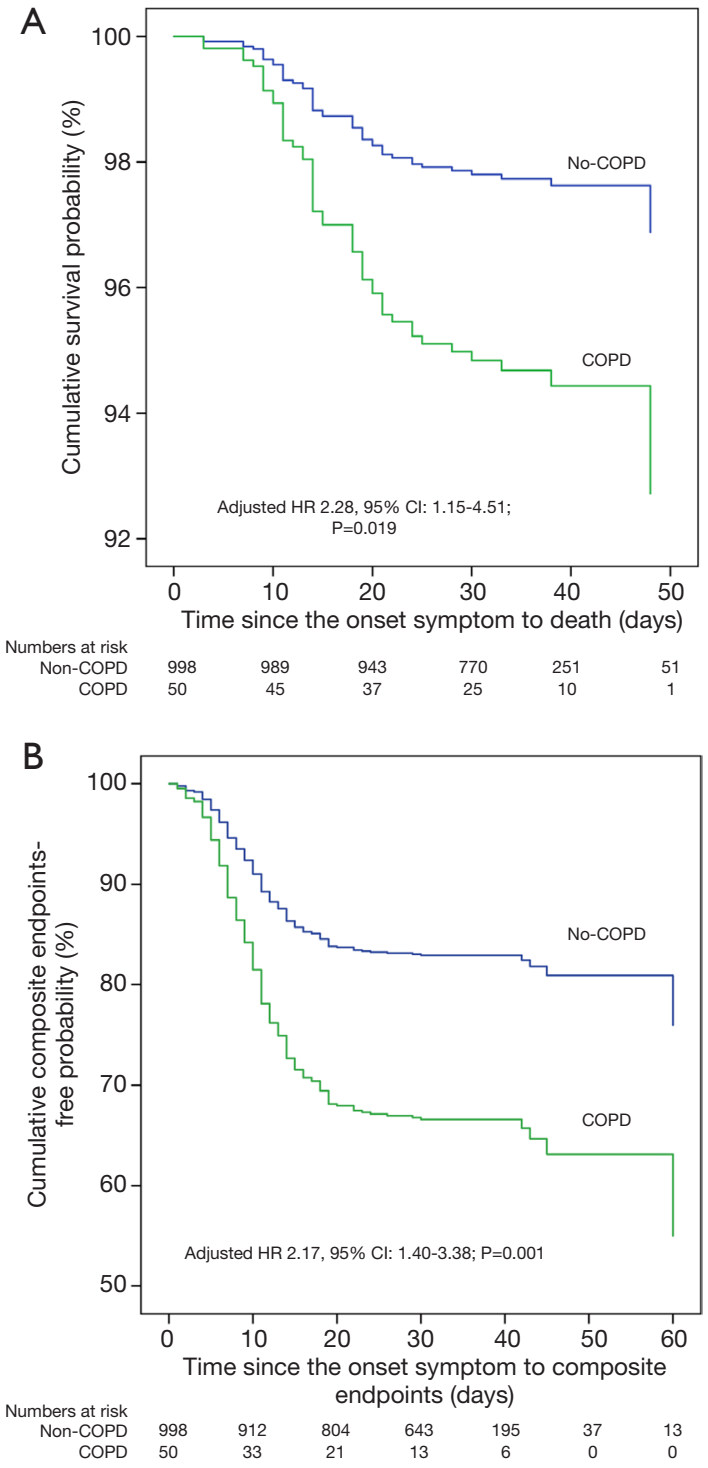

Figure 2 Comparison of the time-dependent risk of clinical outcomes. Compared with patients who had COVID-19 but not COPD, those with COPD had greater likelihood of death (A) and reaching the composite endpoints (B), with an HR of 2.28 (95\% CI: 1.15 to $4.51, \mathrm{P}=0.019$ ) and 2.17 (95\% CI: 1.40 to 3.38 , $\mathrm{P}=0.001$ ), respectively, adjusted by confounding factors including age, sex, smoking status, and other comorbidities.

is consistent with our observations that these patients have more significant differences in their blood test results, more comorbidities, more profound imaging changes, and more rapid disease progression than their counterparts without COPD. Because the main pathologic changes in COPD are characterized by small airway disease, emphysema, and chronic inflammation of the airways, it is well known that patients with COPD have lower basal lung function, abnormal lung structure, and dysfunctional immunity (16-19). In COPD combined with COVID-19, the risk for severe acute exacerbation of COPD caused by viral infection is likely to be higher, resulting in a poor prognosis.

A Chinese nationwide study showed that the proportion of patients with COPD and COVID-19 was $2.4 \%$. A study in the United States revealed that the percentage of patients with COVID-19 as an underlying chronic lung disease was $9.2 \%$; these rates were lower than the proportion with chronic lung disease reported in previous epidemiologic studies in those countries, possibly owing to missing data, underdiagnosis or poor recognition of chronic respiratory diseases in patients with COVID-19 (5,6,20). Regardless of the cause, given the large population with chronic lung disease and the poor prognosis in those patients who develop COVID-19, greater attention is needed for people with chronic lung disease, including patients with COPD (21).

Many studies have reported an increased risk of cardiovascular events in patients with acute exacerbation of COPD, especially within the first 30 days after acute exacerbation (22-24). Therefore, in addition to paying greater attention to the treatment of patients with COPD and COVID-19 during hospitalization, it is also important to follow up these patients for some time after rehabilitation, to further reduce mortality (25).

This large cohort study provides an important reference for the clinical diagnosis and treatment of patients with COPD and COVID-19. Considering the severity and poor prognosis of these patients, it is necessary to strengthen monitoring of their condition and to provide more active multidisciplinary treatments. For patients with COPD who do not have COVID-19, especially those living in endemic areas, personal protection is strongly recommended, even if they are in a stable COPD phase. Once symptoms such as cough, sputum production, or shortness of breath appear in patients with COPD, nucleic acid testing for severe acute respiratory syndrome coronavirus 2 is required to identify novel coronavirus pneumonia, in addition to conventional treatment for acute exacerbation of COPD.

This study has some limitations. First, this was a retrospective study and some patients with COPD and COVID-19 were still in the hospital. Although our data can serve as reference regarding the clinical characteristics and prognosis of patients with COPD and COVID-19, a prospective large-sample cohort study is still needed. 
Second, the baseline characteristics of the two patient groups were not equal. The COPD group was older and had more comorbidities than the non-COPD group, which may affect comparisons of the study endpoints. However, this is unlikely to influence our conclusions as the data were analyzed using multifactor adjustment in Cox proportional hazards analysis, which included adjustment for sex, age, smoking status, and other underlying diseases. Finally, owing to the contagiousness of COVID-19, no lung function testing was conducted on admission to the hospital; therefore, patient's baseline lung function data were unavailable. Furthermore, only some patients with COVID-19 underwent imaging investigation for COPD diagnosis owing to rapid progression of their disease. However, our diagnosis of COPD should be reliable as it was based on the medical history including records of lung function tests (post-bronchodilation $\mathrm{FEV}_{1} / \mathrm{FVC}<0.7$ ) and previous symptoms (cough, expectoration, shortness of breath, and so on).

In summary, we performed a systematic analysis of the clinical characteristics and prognosis of patients with COPD and COVID-19 and found that these patients showed more severe clinical manifestations, a higher rate of ICU admission, had greater mechanical ventilation requirements and higher mortality than their counterparts without COPD, leading to a poor prognosis in the former patient group. These results suggest that greater attention is needed for patients with COPD who develop COVID-19. Our findings highlight the importance of early detection, isolation and treatment, and multidisciplinary intervention for patients with COPD and COVID-19.

\section{Acknowledgments}

We thank Bijia Lin, Peiyu Huang, Shaodan Wei, Xiaopeng Lin (State Key Laboratory of Respiratory Disease \& National Clinical Research Center for Respiratory Disease, Guangzhou Institute of Respiratory Health, the First Affiliated Hospital of Guangzhou Medical University, Nanshan Medicine Innovation Institute of Guangdong Province), Jianwu Xu, Jingwen Li, Zhishan Deng, Zihui Wang, Ge Bai, Shan Xiao, Xinyuan Liu, Youlan Zheng, Xiang Wen, Huajing Yang, Tao Wang, Chunli Tang (State Key Laboratory of Respiratory Disease \& National Clinical Research Center for Respiratory Disease, Guangzhou Institute of Respiratory Health, the First Affiliated Hospital of Guangzhou Medical University), Huanhuan Fan (Guangzhou Medical University), Muqing
Yu, Ke Wang (Department of Pulmonary and Critical Care Medicine, Tongji Hospital, Tongji Medical College, Huazhong University of Science and Technology), Hui Peng, Lixian Xu (Guangzhou Eight People's Hospital, Guangzhou Medical University), Xiaopeng Feng (Huizhou First Hospital), Ling Peng, Lei Liu (Shenzhen Third People's Hospital) for their efforts in collecting the information and verification. We thank Nanshan Medical Development Foundation of Guangdong Province for its support. We also thank all the patients who consented to donate their data for analysis and the medical staffs working in the front line.

Funding: None.

\section{Footnote}

Provenance and Peer Review: This article was submitted to fTD as a revised version along with the incisive peer review comments after rejection from another esteemed journal. Given the revisions and the wide concern and pressing importance of research relating to COVID-19, the article was managed via the rapid communication pathway and underwent internal review within 6 days.

Reporting Checklist: The authors have completed the STROBE reporting checklist. Available at http://dx. doi. org/10. 21037/jtd-20-1914

Data Sharing Statement: Available at http://dx. doi. org/10. 21037/jtd-20-1914

Conflicts of Interest: All authors have completed the ICMJE uniform disclosure form (available at http://dx.doi. org/10.21037/jtd-20-1914). NZ serves as the unpaid Editorin Chief of Fournal of Thoracic Disease. The other authors have no conflicts of interest to declare.

Ethical Statement: The authors are accountable for all aspects of the work in ensuring that questions related to the accuracy or integrity of any part of the work are appropriately investigated and resolved. This was a retrospective case study. The Ethics Commission of the First Affiliated Hospital of Guangzhou Medical University approved the study (No. 2020-51). Because of the urgent need to collect data on this emerging infectious disease, the requirement for written informed consent was waived.

Open Access Statement: This is an Open Access article 
distributed in accordance with the Creative Commons Attribution-NonCommercial-NoDerivs 4.0 International License (CC BY-NC-ND 4.0), which permits the noncommercial replication and distribution of the article with the strict proviso that no changes or edits are made and the original work is properly cited (including links to both the formal publication through the relevant DOI and the license). See: https://creativecommons.org/licenses/by-nc-nd/4.0/.

\section{References}

1. Zhu N, Zhang D, Wang W, et al. A Novel Coronavirus from Patients with Pneumonia in China, 2019. N Engl J Med 2020;382:727-33.

2. Zhou P, Yang XL, Wang XG, et al. A pneumonia outbreak associated with a new coronavirus of probable bat origin. Nature 2020;579:270-3.

3. CSSE JHU. COVID-19 Dashboard by the Center for Systems Science and Engineering (CSSE). Available online: https://www.arcgis.com/apps/opsdashboard/index. html\#/bda7594740fd40299423467b48e9ecf6. Accessed May 112020.

4. Guan WJ, Ni ZY, Hu Y, et al. Clinical Characteristics of Coronavirus Disease 2019 in China. N Engl J Med 2020;382:1708-20.

5. Wang $\mathrm{C}, \mathrm{Xu} \mathrm{J}$, Yang $\mathrm{L}$, et al. Prevalence and risk factors of chronic obstructive pulmonary disease in China (the China Pulmonary Health $[\mathrm{CPH}]$ study): a national cross-sectional study. Lancet 2018;391:1706-17.

6. Guan WJ, Liang WH, Zhao Y, et al. Comorbidity and its impact on 1590 patients with Covid-19 in China: A Nationwide Analysis. Eur Respir J 2020;55:2000547.

7. Yang X, Yu Y, Xu J, et al. Clinical course and outcomes of critically ill patients with SARS-CoV-2 pneumonia in Wuhan, China: a single-centered, retrospective, observational study. Lancet Respir Med 2020;8:475-81.

8. World Health Organization. Laboratory testing for 2019 novel coronavirus (2019-nCoV) in suspected human cases. Available online: https://www.who.int/publicationsdetail/laboratory-testing-for-2019-novel-coronavirus-insuspected-human-cases-20200117. Accessed Jan 172020.

9. Huang C, Wang Y, Li X, et al. Clinical features of patients infected with 2019 novel coronavirus in Wuhan, China. Lancet 2020;395:497-506.

10. GOLD. Global Strategy for the Diagnosis, Management, and Prevention of Chronic Obstructive Pulmonary Disease: 2020 REPORT. Available online: https://goldcopd.org/wp-content/uploads/2019/12/
GOLD-2020-FINAL-ver1.2-03Dec19_WMV.pdf. Accessed April 152020.

11. World Health Organization. Clinical management of severe acute respiratory infection when novel coronavirus $(\mathrm{nCoV})$ infection is suspected. Available online: https://www.who.int/publications-detail/ clinical-management-of-severe-acute-respiratoryinfection-when-novel-coronavirus-(ncov)-infection-issuspected. Accessed Jan 282020.

12. National Health Commission of the People's Republic of China. Available online: http://www.nhc.gov.cn/xcs/ yqtb/202003/c588ee20113b4136b27f2a07faa7075b.shtml. Accessed Mar 32020.

13. Chen N, Zhou M, Dong X, et al. Epidemiological and clinical characteristics of 99 cases of 2019 novel coronavirus pneumonia in Wuhan, China: a descriptive study. Lancet 2020;395:507-13.

14. Wu Z, McGoogan JM. Characteristics of and Important Lessons From the Coronavirus Disease 2019 (COVID-19) Outbreak in China: Summary of a Report of 72314 Cases From the Chinese Center for Disease Control and Prevention. JAMA 2020. doi: 10.1001/jama.2020.2648.

15. Lange P, Celli B, Agusti A, et al. Lung-Function Trajectories Leading to Chronic Obstructive Pulmonary Disease. N Engl J Med 2015;373:111-22.

16. McDonough JE, Yuan R, Suzuki M, et al. Small-airway obstruction and emphysema in chronic obstructive pulmonary disease. N Engl J Med 2011;365:1567-75.

17. Barnes PJ. Inflammatory mechanisms in patients with chronic obstructive pulmonary disease. J Allergy Clin Immunol 2016;138:16-27.

18. Agustí A, Hogg JC. Update on the Pathogenesis of Chronic Obstructive Pulmonary Disease. N Engl J Med 2019;381:1248-56.

19. Putman RK, Hatabu H, Araki T, et al. Association Between Interstitial Lung Abnormalities and All-Cause Mortality. JAMA 2016;315:672-81.

20. CDC COVID-19 Response Team. Preliminary estimates of the prevalence of selected underlying health conditions among patients with coronavirus disease 2019 - United States, February 12-March 28, 2020. 2020. Available online: https://www.cdc.gov/mmwr/volumes/69/wr/pdfs/ mm6913e2-H.pdf. Accessed March 282020.

21. Halpin DMG, Faner R, Sibila O, et al. Do chronic respiratory diseases or their treatment affect the risk of SARS-CoV-2 infection? Lancet Respir Med 2020;8:436-8.

22. Kunisaki KM, Dransfield MT, Anderson JA, et al. Exacerbations of Chronic Obstructive Pulmonary Disease 
and Cardiac Events. A Post Hoc Cohort Analysis from the SUMMIT Randomized Clinical Trial. Am J Respir Crit Care Med 2018;198:51-7.

23. Wang M, Lin EP, Huang LC, et al. Mortality of cardiovascular events in COPD patients with preceding hospitalized acute exacerbation. Chest 2020. doi: 10.1016/ j.chest.2020.02.046.

24. Hartl S, Lopez-Campos JL, Pozo-Rodriguez F, et al. Risk

Cite this article as: $\mathrm{Wu} F$, Zhou $\mathrm{Y}$, Wang Z, Xie M, Shi Z, Tang Z, Li X, Li X, Lei C, Li Y, Ni Z, Hu Y, Liu X, Yin W, Cheng L, Ye F, Peng J, Huang L, Tian J, Zhang L, Mo X, Zhang Y, Hu K, Jiang Y, Guan W, Xiang J, Liu Y, Peng Y, Wei L, Hu Y, Peng P, Wang J, Liu J, Huang W, Chen R, Zhao J, Li S, Zhang N, Zhao J, Zhong N, Ran P; for the Medical Treatment Expert Group for COPD and COVID-19. Clinical characteristics of COVID-19 infection in chronic obstructive pulmonary disease: a multicenter, retrospective, observational study. J Thorac Dis 2020;12(5):1811-1823. doi: 10.21037/jtd20-1914 of death and readmission of hospital-admitted COPD exacerbations: European COPD Audit. Eur Respir J 2016;47:113-21.

25. Puhan MA, Gimeno-Santos E, Cates CJ, et al. Pulmonary rehabilitation following exacerbations of chronic obstructive pulmonary disease. Cochrane Database Syst Rev 2016;12:CD005305. 


\section{The source of subjects and hospitals}

In this study, the patients were recruited from two different sources list as follows: (I) Before Jan 29th, we recruited 12 chronic obstructive pulmonary disease (COPD) patients with coronavirus disease 2019 (COVID-19), and 593 COVID-19 patients without COPD at the age of 40 years and above from the data processing center of the National Health Commission of the People's Republic of China in Guangzhou. (II) from Jan 30th to Feb 20th the other patients, including 38 COVID-19 patients with COPD and 405 COVID-19 patients without COPD at the age of 40 years and above, were recruited from some designated hospitals for COVID-19 in Hubei, Hunan and Guangdong Province. The COPD patients in this study were recruited respectively from the data processing center of the National Health Commission of the People's Republic of China in Guangzhou (12 patients), Tongji Hospital of Huazhong University of Science and Technology (11 patients), Union Hospital of Huazhong University of Science and Technology (7 patients), The First Affiliated Hospital of Guangzhou Medical University (4 patients), Shenzhen Third People's Hospital of Guangdong Province (4 patients), Renmin Hospital of Wuhan University (3 patients), Guangzhou Eighth People's Hospital of Guangzhou Medical University (3 patients), The First People's Hospital of Yueyang of Hunan Province (3 patients), The Second Peoples Hospital of Changde City of Hunan Province (2 patients) and Jiangling County People's Hospital of Hubei Province (1 patient). 
Table S1 Clinical characteristics of the study population

\begin{tabular}{|c|c|c|c|c|c|}
\hline Characteristics & $\operatorname{COPD}(\mathrm{N}=38)$ & Non-COPD (N=405) & $P$ values & $\begin{array}{l}\text { Adjusted OR }(95 \% \mathrm{Cl}) \\
\text { (COPD vs. non-COPD) }^{*}\end{array}$ & $\begin{array}{l}P \text { values for } \\
\text { adjustment }\end{array}$ \\
\hline Age, median (IQR) (years) & $69.5(65.8-76.5)$ & $55.0(47.0-64.9)$ & $<0.001$ & - & - \\
\hline Age groups, No./total No. (\%) & & & $<0.001$ & - & - \\
\hline $40-49$ years & $0 / 38(0.0)$ & $130 / 405(32.1)$ & & & \\
\hline $50-59$ years & 2/38 (5.3) & $117 / 405(28.9)$ & & & \\
\hline $60-69$ years & $17 / 38(44.7)$ & $107 / 405(26.4)$ & & & \\
\hline $70-79$ years & 13/38 (34.2) & $43 / 405(10.6)$ & & & \\
\hline$\geq 80$ years & 6/38 (15.8) & $8 / 405(2.0)$ & & & \\
\hline Male, No./total No. (\%) & $34 / 38(89.5)$ & 233/405 (57.5) & $<0.001$ & - & - \\
\hline Smoking history, No./total No. (\%) & & & $<0.001$ & - & - \\
\hline Never smokers & $17 / 38(44.7)$ & $355 / 405(87.7)$ & & & \\
\hline Smoking & 20/38 (52.6) & $47 / 405(11.6)$ & & & \\
\hline Ex-smokers & $17 / 20(85.0)$ & $37 / 47(78.7)$ & & & \\
\hline Current smokers & $3 / 20(15.0)$ & $10 / 47(21.3)$ & & & \\
\hline Coexisting disorders, No./total No. (\%) & & & & - & - \\
\hline Any & $38 / 38(100.0)$ & $135 / 405(33.3)$ & $<0.001$ & & \\
\hline Diabetes & 6/38 (15.8) & $46 / 405(11.4)$ & 0.42 & & \\
\hline Hypertension & $13 / 38(38.0)$ & $91 / 405(22.5)$ & 0.10 & & \\
\hline Coronary heart disease & 6/38 (15.8) & $20 / 405(4.9)$ & 0.017 & & \\
\hline Cerebrovascular diseases & 7/38 (18.4) & $8 / 405(2.0)$ & $<0.001$ & & \\
\hline Hepatitis B infection & $1 / 38(2.6)$ & $11 / 405(2.7)$ & 0.98 & & \\
\hline Cancer & $1 / 38(2.6)$ & 6/405 (1.5) & 0.47 & & \\
\hline Chronic renal diseases & $3 / 38(7.9)$ & $7 / 405(1.7)$ & 0.046 & & \\
\hline Immunodeficiency & $0 / 38(0.0)$ & 0/405 (0.2) & & & \\
\hline \multicolumn{6}{|l|}{ Symptoms, No./total No. (\%) } \\
\hline Conjunctival congestion & $0 / 38(0.0)$ & $0 / 405(0.0)$ & & & \\
\hline Nasal congestion & $1 / 38(2.0)$ & $20 / 405(4.9)$ & 0.52 & & \\
\hline Headache & 2/38 (5.3) & $55 / 405(13.6)$ & 0.20 & & \\
\hline Cough & 23/38 (60.5) & 278/405 (68.6) & 0.31 & & \\
\hline Sore throat & $4 / 38(10.5)$ & $38 / 405(9.4)$ & 0.77 & & \\
\hline Sputum production & $8 / 38(21.1)$ & $137 / 405(33.8)$ & 0.11 & & \\
\hline Fatigue & 23/38 (60.5) & $171 / 405(42.2)$ & 0.030 & $3.44(1.51-7.83)$ & 0.003 \\
\hline Hemoptysis & $1 / 38(2.6)$ & $5 / 405(1.2)$ & 0.42 & & \\
\hline Shortness of breath & $27 / 38(71.1)$ & $108 / 405(26.7)$ & $<0.001$ & $5.46(2.22-13.41)$ & $<0.001$ \\
\hline Nausea or vomiting & $2 / 38(5.3)$ & $21 / 405(5.2)$ & 0.98 & & \\
\hline Diarrhea & $8 / 38(21.1)$ & $13 / 405(3.2)$ & $<0.001$ & $5.45(1.51-19.66)$ & 0.010 \\
\hline Myalgia or arthralgia & 6/38 (15.8) & $58 / 405(14.3)$ & 0.81 & & \\
\hline Chill & $3 / 38(7.9)$ & $57 / 405(14.1)$ & 0.29 & & \\
\hline Signs, No./total No. (\%) & & & & - & - \\
\hline Temperature & & & & - & - \\
\hline $\begin{array}{l}\text { Fever during hospitalization, } \\
\text { No./total No. (\%) }\end{array}$ & $34 / 38(89.5)$ & $352 / 405$ (86.9) & 0.80 & & \\
\hline $\begin{array}{l}\text { Median temperature } \\
\text { on admission (IQR), }{ }^{\circ} \mathrm{C}\end{array}$ & $37.0(36.5-37.7)$ & $37.2(36.6-38.0)$ & 0.42 & & \\
\hline $\begin{array}{l}\text { Distribution of temperature } \\
\text { on admission, No./total No. (\%) }\end{array}$ & & & 0.55 & & \\
\hline$<37.5$ & $26 / 37(70.3)$ & $239 / 390(61.3)$ & & & \\
\hline $37.5-38.5$ & $8 / 37(21.6)$ & $105 / 390(26.9)$ & & & \\
\hline$>39$ & $3 / 37(8.1)$ & $46 / 390(11.8)$ & & & \\
\hline $\begin{array}{l}\text { Respiratory rate on admission (IQR), } \\
\text { breaths/min }\end{array}$ & 21 [20-28] & 20 [20-21] & 0.011 & & \\
\hline Throat congestion & $0 / 38(0.0)$ & $6 / 405(1.5)$ & 0.45 & & \\
\hline Tonsil swelling & $0 / 38(0.0)$ & $8 / 405(2.0)$ & 0.38 & & \\
\hline Enlargement of lymph nodes & $0 / 38(0.0)$ & $0 / 405(0.1)$ & & & \\
\hline Rash & $0 / 38(0.0)$ & $1 / 405(0.2)$ & 0.76 & & \\
\hline Unconscious & $3 / 38(7.9)$ & 6/405 (1.5) & 0.034 & $7.13(1.11-46.02)$ & 0.039 \\
\hline
\end{tabular}

Data are mean \pm standard deviation, $\mathrm{n}(\%)$, or median (interquartile range). $\mathrm{P}$ values for continuous variables were calculated by Student's $t$-test or the Wilcoxon rank-sum test, and $\mathrm{P}$ values for categorical variables were calculated by the chi-square test or Fisher's exact test. *, adjusted for age, sex, smoking status and other comorbidities (including diabetes, hypertension, coronary heart disease, cerebrovascular diseases, hepatitis $B$ infection, cancer, chronic renal diseases, immunodeficiency), no significance $(P \geq 0.05)$ was not shown in the table. Odds ratio $>1$ means that more people in COPD than non-COPD in variables. 
Table S2 Laboratory and radiographic findings among patients who had COVID-19, with or without COPD on admission

\begin{tabular}{|c|c|c|c|c|c|}
\hline Variables & $\begin{array}{l}\text { COPD } \\
(n=38)\end{array}$ & $\begin{array}{l}\text { Non-COPD } \\
(\mathrm{n}=405)\end{array}$ & $P$ values & $\begin{array}{l}\text { Adjusted OR }(95 \% \mathrm{Cl}) \\
\text { (COPD vs. non-COPD)* }\end{array}$ & $\begin{array}{l}P \text { values for } \\
\text { adjustment }\end{array}$ \\
\hline \multicolumn{6}{|l|}{ Laboratory findings } \\
\hline Median $\mathrm{SpO}_{2}(\mathrm{IQR}), \%$ & 95 [82-98] & 96 [94-98] & 0.23 & & \\
\hline Blood leukocyte count $\left(10^{9} / \mathrm{L}\right)$ & & & 0.11 & & \\
\hline$<4$ & $5 / 34(14.7)$ & $110 / 353(31.2)$ & & & \\
\hline $4-10$ & 24/34 (70.6) & $211 / 353(59.8)$ & & & \\
\hline$>10$ & $5 / 34(14.7)$ & $32 / 353(9.1)$ & & & \\
\hline Platelet count $\left(10^{9} / \mathrm{L}\right)$ & & & 0.58 & & \\
\hline$<100$ & $5 / 35(14.3)$ & $36 / 319(11.3)$ & & & \\
\hline$\geq 100$ & $30 / 35(85.7)$ & $283 / 319(88.7)$ & & & \\
\hline Lymphocyte count $\left(10^{9} / \mathrm{L}\right)$ & & & 0.47 & & \\
\hline$<0.8$ & 13/34 (38.2) & $93 / 330(28.2)$ & & & \\
\hline $0.8-1.1$ & $9 / 34(26.5)$ & $106 / 330(32.1)$ & & & \\
\hline$\geq 1.1$ & 12/34 (35.3) & $131 / 330(39.7)$ & & & \\
\hline APTT $>45$ (s) & $7 / 26(26.9)$ & $13 / 241(5.4)$ & $<0.001$ & & \\
\hline Prothrombin time (s) & & & 0.07 & & \\
\hline$<11$ & $1 / 27(3.7)$ & $55 / 242(2.7)$ & & & \\
\hline $11-15$ & 24/27 (88.9) & $172 / 242(71.1)$ & & & \\
\hline$>15$ & $2 / 27(7.4)$ & $15 / 242(6.2)$ & & & \\
\hline $\begin{array}{l}\text { Anemia ( }<120 \text { in male and }<110 \mathrm{~g} / \mathrm{dL} \text { in } \\
\text { female) }\end{array}$ & $9 / 30(30.0)$ & $81 / 321(25.2)$ & 0.57 & & \\
\hline C-reactive protein level $\geq 10 \mathrm{mg} / \mathrm{L}$ & $31 / 33(93.9)$ & 236/295 (80.0) & 0.05 & & \\
\hline Procalcitonin level $\geq 0.5 \mathrm{ng} / \mathrm{mL}$ & 24/32 (75.0) & $150 / 248(60.5)$ & 0.11 & & \\
\hline Lactose dehydrogenase $\geq 250 \mathrm{U} / \mathrm{L}$ & 21/32 (65.6) & 130/262 (49.6) & 0.09 & & \\
\hline Aspartate aminotransferase $>40 \mathrm{U} / \mathrm{L}$ & $10 / 33(30.3)$ & $86 / 286(30.1)$ & 0.98 & & \\
\hline Alanine aminotransferase $>40 \mathrm{U} / \mathrm{L}$ & 5/33 (15.2) & $47 / 277(17.0)$ & 0.79 & & \\
\hline Creatinine $(\mu \mathrm{mol} / \mathrm{L})$ & $137.1 \pm 193.2$ & $74.3 \pm 45.1$ & $<0.001$ & & \\
\hline Total bilirubin $>17.1 \mu \mathrm{mol} / \mathrm{L}$ & $1 / 33(3.0)$ & $12 / 267(4.5)$ & 0.70 & & \\
\hline Creatinine kinase $\geq 200 \mathrm{U} / \mathrm{L}$ & $5 / 26(19.2)$ & 39/256 (15.2) & 0.57 & & \\
\hline $\mathrm{D}$-dimer $\geq 0.5 \mathrm{mg} / \mathrm{L}$ & 23/34 (67.6) & 66/234 (28.2) & $<0.001$ & $3.69(1.38-9.80)$ & 0.009 \\
\hline Sodium (mmol/L) & $137.6 \pm 5.3$ & $141.2 \pm 61.3$ & 0.77 & & \\
\hline Potassium (mmol/L) & $4.0 \pm 0.7$ & $3.8 \pm 0.6$ & 0.20 & & \\
\hline Chloride (mmol/L) & $103.6 \pm 6.9$ & $103.7 \pm 4.8$ & 0.96 & & \\
\hline Albumin (g/L) & $34.1 \pm 7.4$ & $37.5 \pm 8.0$ & 0.018 & & \\
\hline \multicolumn{6}{|l|}{ Radiographic findings } \\
\hline \multicolumn{6}{|c|}{ Abnormalities on chest X-ray, No./total No. (\%) } \\
\hline Any abnormalities & $9 / 13(69.2)$ & $85 / 117(72.6)$ & 0.75 & & \\
\hline Ground-glass opacity & $6 / 13(46.2)$ & $34 / 117(29.1)$ & 0.21 & & \\
\hline Local patchy shadowing & $7 / 13(53.8)$ & $40 / 117(34.2)$ & 0.22 & & \\
\hline Bilateral patchy shadowing & $7 / 13(53.8)$ & $65 / 117(55.6)$ & 0.91 & & \\
\hline Interstitial abnormalities & 2/13 (15.4) & 10/117 (8.5) & 0.34 & & \\
\hline \multicolumn{6}{|l|}{ Abnormalities on chest CT, No./total No. (\%) } \\
\hline Any abnormalities & $34 / 37(91.9)$ & $310 / 356(87.1)$ & 0.60 & & \\
\hline Ground-glass opacity & $32 / 37(86.5)$ & $218 / 356(61.2)$ & 0.002 & $6.19(1.99-19.19)$ & 0.002 \\
\hline Local patchy shadowing & 26/37 (70.3) & $164 / 356(46.1)$ & 0.005 & $3.22(1.30-7.95)$ & 0.011 \\
\hline Bilateral patchy shadowing & 26/37 (70.3) & $198 / 356(55.6)$ & 0.09 & & \\
\hline Interstitial abnormalities & 20/37 (54.1) & 76/356 (21.3) & $<0.001$ & $4.96(2.02-12.13)$ & $<0.001$ \\
\hline
\end{tabular}

$P$ values for continuous variables were calculated by Student's $t$-test or the Wilcoxon rank-sum test, and $P$ values for categorical variables were calculated by the chi-square test or Fisher's exact test. *, adjusted for age, sex, smoking status and other comorbidities (including diabetes, hypertension, coronary heart disease, cerebrovascular diseases, hepatitis B infection, cancer, chronic renal diseases, immunodeficiency), no significance $(P \geq 0.05)$ was not shown in the table. Odds ratio $>1$ means that more people in COPD than non-COPD in variables. COVID-19, coronavirus disease 2019; COPD, chronic obstructive pulmonary; IQR, interquartile range; $\mathrm{SpO}_{2}$, saturation of pulse oxygen; APTT, activated partial thromboplastin time; CT, computed tomography. 
Table S3 Complications, treatments, and clinical outcomes of patients who had COVID-19, with COPD or without COPD

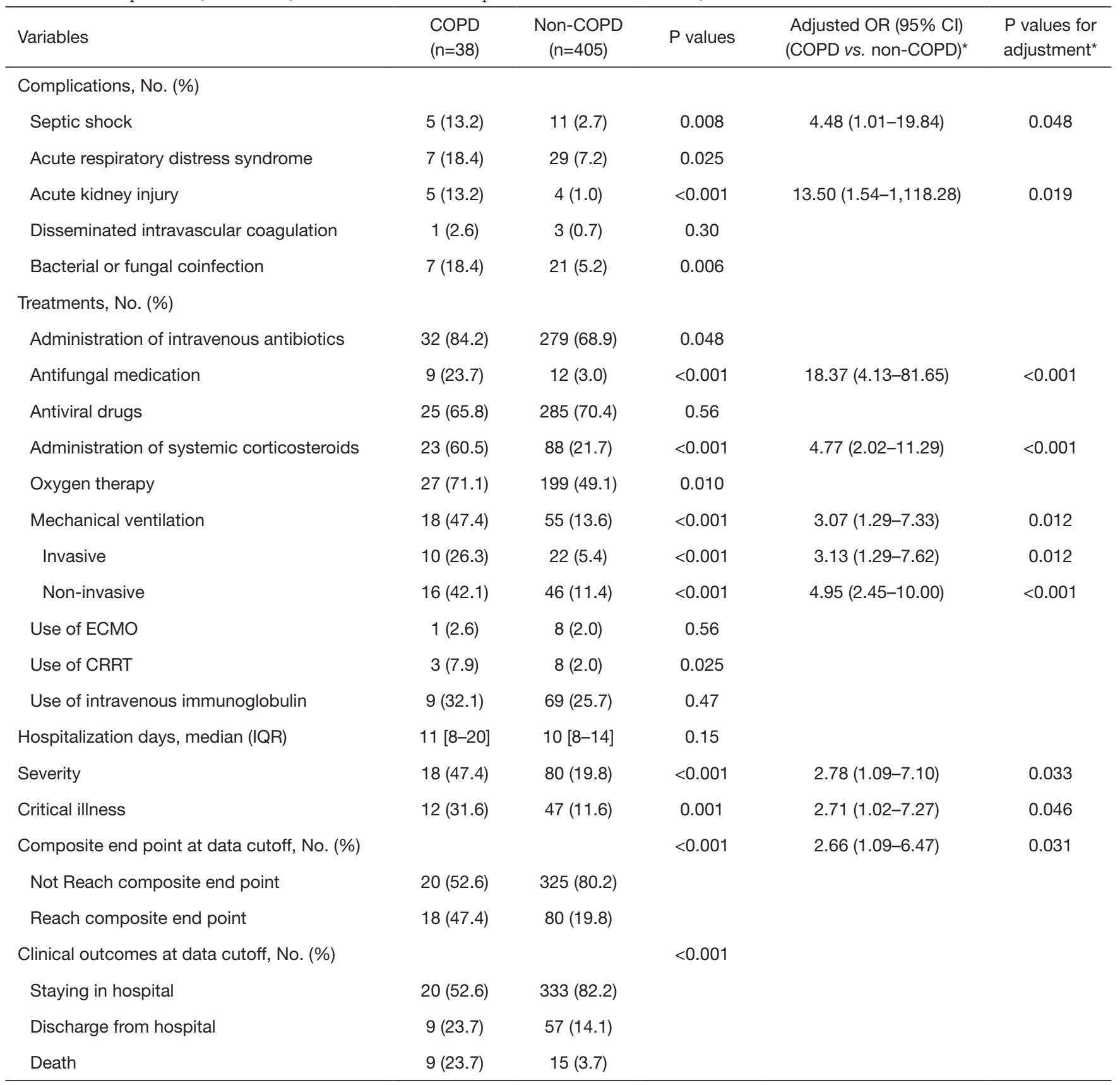

$P$ values for categorical variables were calculated by the chi-square test or Fisher's exact test. *, adjusted for age, sex, smoking status and other comorbidities (including diabetes, hypertension, coronary heart disease, cerebrovascular diseases, hepatitis B infection, cancer, chronic renal diseases, immunodeficiency), no significance $(\mathrm{P} \geq 0.05)$ was not shown in the table. Odds ratio $>1$ means that more people in COPD than non-COPD in variables. Composite end point determined by the admission to an ICU, the use of mechanical ventilation, or death. COVID-19, coronavirus disease 2019; COPD, chronic obstructive pulmonary disease; ECMO, extracorporeal membrane oxygenation; CRRT, continuous renal replacement therapy; IQR, interquartile range. 

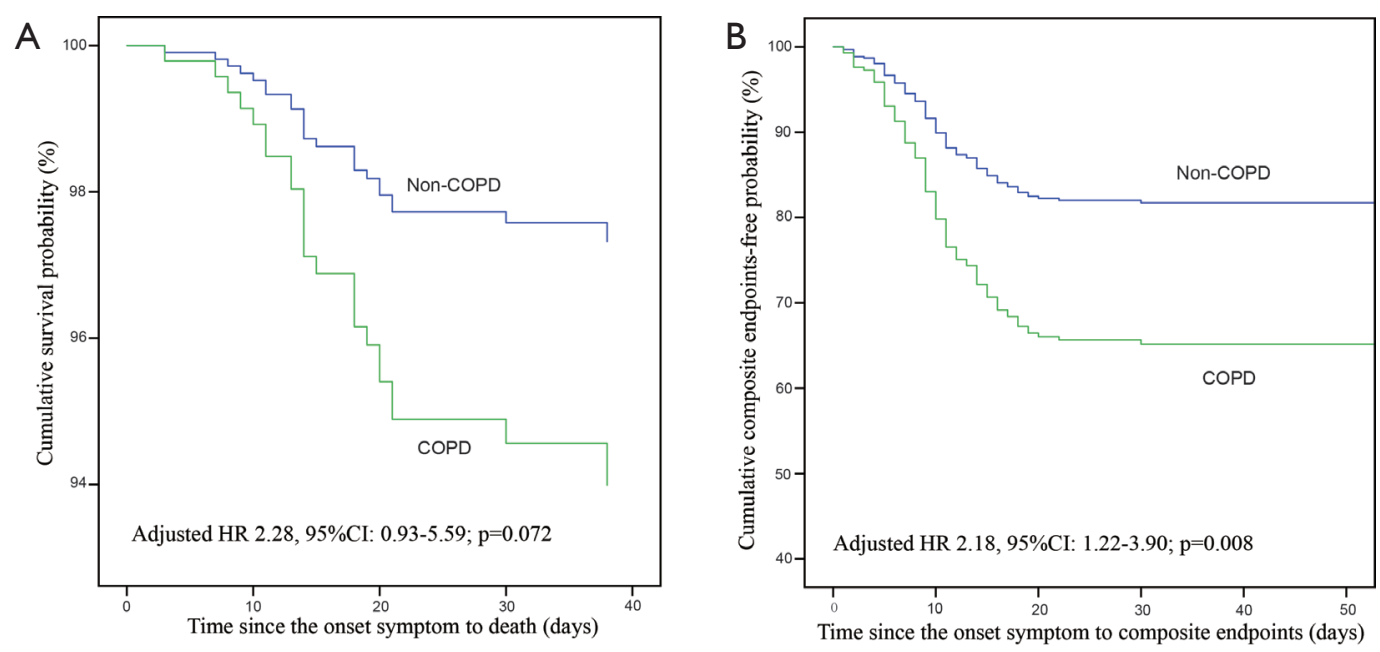

Figure S1 Comparison of the time-dependent risk of clinical outcomes. 